Estudios de la Paz y el Conflicto

Revista Latinoamericana

IUDPAS-UNAH

Volumen 1, Número 2, pp. 92-110

ISSN-e: 2707-8922 | ISSN: 2707-8914

DOI: $10.5377 /$ rlpc.v1i2.9836

Julio-diciembre 2020

\title{
CONFLICTOS ESTRUCTURALES: ELEMENTOS PARA INTERVENCIÓN EN CONFLICTOS CRÓNICOS
}

\author{
STRUCTURAL CONFLICTS: \\ ELEMENTS FOR INTERVENTION IN CHRONIC CONFLICTS
}

\author{
Josep Redorta \\ Abogado. Conflict Manager. Doctor en Psicología Social \\ josepredorta@icab.cat
}

Recibido: 29-04-2020

Aceptado: 25-05-2020

Cómo citar / citation

Redorta, J. (2020). "Conflictos estructurales: elementos para intervención en conflictos crónicos", Estudios de la Paz y el Conflicto, Revista Latinoamericana, Volumen 1, Número 2, 92-110. DOI: $10.5377 /$ rlpc.v1i2.9836

\section{Resumen}

Se sitúa la conflictología en el marco de los Peace and Conflict Studies con orientación a los conflictos estructurales. Se debaten las dificultades de la comprensión de los conflictos en general, especificando los factores que influyen en una intervención. Se perfila la idea de conflictos estructurales y sus elementos. Se especifica cómo se cronifican los conflictos y el rol de la ideología y la concienciación de lo que sucede. Se considera el rol de la confianza en relaciones conflictivas. Se examinan las relaciones de poder y sus efectos: obediencia, reactancia psicológica, indefensión aprendida y dependencia, así como las conductas desviadas. Se sugieren algunas bases para una intervención profesional, con distinción entre pequeños grupos y comportamientos colectivos masivos. Se concluye la necesidad de profundizar en esta tipología de conflictos y en mejorar las habilidades de los terceros neutrales.

\section{Palabras clave}

Conflictología; conflictos estructurales; intratabilidad; relaciones poder; cambio social; intervención. 


\begin{abstract}
Conflictology is placed within the framework of Peace and Conflict Studies with a focus on structural conflicts. The difficulties of understanding conflicts in general are discussed by specifying the factors that influence an intervention. The idea of structural conflicts and their elements is outlined. It specifies how conflicts are chronicled and the role of ideology and awareness of what happens. It is considered the role of trust in conflicting relationships. Power relations and their effects are examined: obedience, psychological reactance, learned helplessness, and dependence. As well as misguided behaviors. Some basis for professional interventions is suggested, with distinction between small groups and mass collective behaviors. The need to deepen this type of conflict and to improve the skills of neutral third parties is concluded.
\end{abstract}

\title{
Keywords
}

Conflictology; structural conflicts; intractability; power relations; social change; intervention.

\section{INTRODUCCIÓN: EL CONFLICTO COMO OBJETO DE LA CIENCIA}

Un trabajo de Galtung (2009) asume el término conflictología como una ciencia en construcción de carácter claramente transdisciplinar y cuyo objeto sería el conflicto y sus formas de resolución. Este concepto que ya se venía desarrollando sobre todo desde otros científicos de habla hispana $^{1}$, resulta un marco adecuado para englobar los conflictos de todo tipo que aparecen en los diversos niveles. No obstante, la idea de Peace and conflict studies sigue aun siendo la nomenclatura dominante en la ciencia.

A nuestros efectos, hay un grupo de conflictos que realmente importan mucho, en la medida que afectan a gran número de personas: son conflictos que tienen que ver con la guerra y la paz, la violencia en general, la explotación de recursos naturales, las relaciones de poder, el desarrollo de los pueblos, las religiones y los valores en general. Es en este punto, donde creemos que la conflictología tiene mucho que aportar desde un punto de vista conceptual.

La frontera entre conflictos "intratables" y aquellos otros "tratables" creemos que es una distinción poco afortunada. Es cierto que la clasificación es una condición previa y necesaria para la generalización, como afirma Mitchell (2014: 91). Sin embargo, las fronteras clasificatorias en los conflictos solamente pueden ser entendidas dentro del ámbito de la imprecisión. Es decir, considerando una amplia zona de grises. Afirma Kosko (1995:21) que hay un problema de discordancia: "el mundo es gris, pero la ciencia es blanca y negra". El propio concepto de intratabilidad ha merecido diversos tratamientos en la literatura donde el acento se ha puesto llamándoles deep-rooted conflicts. Al fin, el propio Mitchell (2014:87). en su reciente obra La naturaleza de los conflictos intratables, conviene en que se hace preciso analizar porqué unos conflictos en su dinámica se hacen intratables y otros no ${ }^{2}$.

\footnotetext{
${ }^{1}$ El primero que nos consta que usó este concepto en España fue Vinyamata quien desde la Universidad Oberta de Catalunya en sus numerosos cursos sobre paz y conflicto.

${ }^{2}$ Con un mayor detalle y amplitud véase "Intractable conflicts" de Coleman (2000), citado en la bibliografía. Estudios de la Paz y el Conflicto, Revista Latinoamericana, IUDPAS-UNAH, Volumen 1, Número 2, julio-diciembre 2020, pp. 92-110. DOI: 10.5377/rlpc.v1i2.9836
} 
Vayamos al año 2004 en que Mayer (2004: 9) creemos que acertó cuando planteó una pregunta crucial en estos términos: Where is Conflict Resolution in Major Conflicts? De manera que abrió el debate en la profesión, al remarcar que no se alcanzaba a gestionar tales conflictos con los recursos habituales del sector. En año 2011, Redorta (2011:117) sostenía que: "El estudio de los conflictos de carácter estructural estimamos que carece actualmente de modelos claros de aproximación a los mismos a pesar de la muy diversa literatura existente".

Este aspecto contradictorio de la ciencia, lo puso de manifiesto de manera muy clara Burton (1990) cuando frente al término prevention elaboró el término "provention", cómo un concepto nuevo para explicar su enlace con la teoría de las necesidades humanas. Parece una contradicción que podemos ver en la existencia de un discurso referido a la "prevención de conflictos"3, cuando al mismo tiempo se viene sosteniendo la defensa de aspectos positivos en los mismos, al extremo que el marxismo nos dirá que el conflicto es el motor de la historia.

En definitiva, nos queda un largo camino para recorrer y vamos a tratar de desbrozar en este trabajo algunos aspectos que pueden ser relevantes, sin ánimo exhaustivo. En particular, nos interesan aspectos vinculados a conflictos que se arrastran en el tiempo.

\section{EL PROBLEMA DE LA COMPRENSIÓN DE LOS CONFLICTOS}

El problema de la comprensión del mundo y de lo humano sobre el que pensamos desde los albores de nuestra civilización, se ha vuelto ahora aún más crítico. Así lo sostiene Morin (2001:113), quien señala que: "hay una ceguera permanente sobre la naturaleza misma de lo que debería ser el conocimiento pertinente". La fragmentación disciplinar del conocimiento no sólo está extendida en la sociedad, sino en la mente de cada individuo de manera que: "se está produciendo una especie de confusión mental generalizada que genera todo tipo de problemas en la forma de pensar" opina Bohm (1988:19). La visión holística del mundo y de las personas es netamente insuficiente. El antropólogo Ury (2000: 23) nos dirá que: "hoy en día no hay ningún desafío más importante que el de abordar nuestras diferencias". Es así, como llegamos a un punto en el que Wagensberg (2012: 14) podrá afirmar que: "la esencia de la tragedia es que el individuo es incapaz de vivir solo, pero también es incapaz de vivir con el otro".

Estamos ante un problema de comprensión. La comprensión es buscar las convergencias dentro de las divergencias ${ }^{4}$ hallar lo uno respecto a lo diverso. Compartir con los demás los significados respecto al mundo. Entonces, el estudio de la divergencia entre personas y sus agrupaciones diversas, debería tener una relevancia fundamental en la ciencia. Y esto no ocurre. Los grandes presupuestos dedicados a la militarización del mundo y la escasísima inversión en cultura de paz y conflictología nos dan la medida del porqué del relativamente escaso avance científico de nuestra área de las ciencias sociales.

Con este planteamiento, el análisis de conflictos pasa a tener un rol relevante en el desarrollo futuro de la conflictología. Necesitamos conocer para actuar. La secuencia

\footnotetext{
3 Un ejemplo claro de esto es en Ury (2000: 199), en cuya obra “Alcanzar la Paz" desarrolla un modelo donde la palabra "prevención" figura como una fase a la que aplicar recursos.

4 Esta es una idea insistente en toda la obra de Wagensberg (2012), físico teórico y gran humanista experto en sistemas complejos recientemente fallecido.

Estudios de la Paz y el Conflicto, Revista Latinoamericana, IUDPAS-UNAH, Volumen 1, Número 2, julio-diciembre 2020, pp. 92-110. DOI: 10.5377/rlpc.v1i2.9836
} 
análisis-pronóstico-intervención respecto de una situación de conflicto, nos parece que contra toda lógica- se ha invertido. Si examinamos la literatura en conflictología (Peace and conflict studies), descubriremos con asombro que hay más material respecto de cómo resolver un conflicto, que sobre cuales sus raíces, quizás con la excepción de las guerras. El análisis de conflictos es un campo que empieza a perfilarse ahora mismo.

En lo que se refiere a pronóstico, podemos afirmar que es un territorio prácticamente no investigado, lo que no deja de ser lógico si somos conscientes de la insuficiencia de nuestras metodologías de análisis. Es ahora cuando, desde el Paradigma de la Complejidad, la Neurobiología y la Inteligencia Artificial, están apareciendo los primeros indicios de que el panorama va a cambiar ${ }^{5}$.

Muchas son las dificultades para analizar debidamente los conflictos. Baste examinar la obra de Yarn (1999: 117-118) Dictionary of Conflict Resolution y ver que dedica al término "conflict analysis" cinco líneas en sus más de 500 páginas. Con el fin darnos una idea inicial más amplia, exploramos vía Google por las palabras clave "conflict analysis" lo que produjo 903.000 referencias. Pero, cuando la misma consulta la efectuamos en el más especializado Google Scholar, el resultado se redujo a 46.900 referencias. Afinamos más añadiendo las siglas ADR (Alternative Dispute Resolution); el resultado final producido fueron 1.250 referencias. Y debemos tener en cuenta que aquí se muestran todos los resultados de todo tipo de conflictos humanos. Es obvio que estamos ante un campo, si bien emergente, aún a desarrollar de manera necesaria.

Para entender mejor la importancia de tener planteamientos claros en lo que respecta a la obtención de resultados detallamos aquellos factores que, a nuestro juicio, deben ser tenidos en cuenta para cualquier tipo de conflicto :

a) Los factores que resultan permanentes en la relación entre las partes. Por ejemplo: la edad, el género, el rol, la historia, etc.

b) Los factores que derivan de la relación que las partes sostienen. Por ejemplo, dependencia, familia, vecindad, afinidad política, etc.

c) Las caracteristicas del conflicto. No se tratan igual los conflictos vinculados a la autoestima, que los conflictos de poder, por poner un ejemplo.

d) Las características del gestor o gestores del conflicto. La suma de habilidades y recursos es muy importante y afecta al resultado final.

En 2011, desarrollamos un modelo general que denominanos S.E.D.A. con la finalidad de ordenar las ideas en orden a la aplicabilidad en cualquier intervención, finalidad última del análisis de conflictos ${ }^{6}$. Para nosotros, conocer, comprender, combinar y actuar serán ejes de lo que vamos a ir desarrollando. Estamos interesados en acercarnos más a los conflictos de orden más estructural ${ }^{7}$.

\section{PERFILANDO LOS CONFLICTOS ESTRUCTURALES}

En la historia de las ideas, el concepto de "estructura" aparece sobre todo en el siglo XX en distintos ámbitos disciplinares. Se refiere a cómo se relacionan las partes respecto al todo. La

\footnotetext{
5 Para una ampliación de estas ideas ver la obra de Wallacher (2013) Bhertoz (2009) y López Mántaras (2018), entre otros autores citadas en la bibliografía.

${ }^{6}$ Véase Redorta (2011: 35), en su obra "Gestión de Conflictos. Lo que necesita saber".

7 Una ampliación de estas ideas en la obra citada precedentemente.

Estudios de la Paz y el Conflicto, Revista Latinoamericana, IUDPAS-UNAH, Volumen 1, Número 2, julio-diciembre 2020, pp. 92-110. DOI: 10.5377/rlpc.v1i2.9836
} 
estructura tiene una función, es decir, sirve para algo. Así, la estructura de una vivienda define lo que cabe dentro de ella y al concebirla el arquitecto ya tiene la idea de que función realizará cualquier elemento ya sea la cocina o el dormitorio.

La sociología y la antropología, como disciplinas, también nacen en el siglo pasado y empiezan a pensar en términos de estructuras sobre todo en Francia donde se forma un movimiento denominado "estructuralismo" cuyo principal representante será Claude LévíStrauss (1987). En 1984 un inglés, Anthony Giddens, plantea las bases para una teoría de la estructuración de las sociedades humanas. Ambas aportaciones y las de otros importantes científicos sociales van a ser muy relevantes.

En realidad, desde la década de los años sesenta se está empezando a pensar en términos de "sistemas". De alguna manera, cuando vemos o descubrimos alguna cosa, empezamos a pensar cómo se relaciona con otros elementos. Así, una mesa tendrá pleno significado si la asociamos a un comedor o a un área de trabajo ${ }^{8}$. Entonces, al pensar el conflicto social, aparece debajo de él, la estructura de la sociedad. Ahora, trata de examinarse la correlación entre unos aspectos permanentes como son los estructurales y las manifestaciones de los conflictos entre personas y grupos humanos. De esta manera, las ciencias sociales empiezan a estudiar específicamente aspectos de la estructura a partir de sus elementos: las religiones, las etnias, la renta y su distribución, las creencias en general, el uso del poder y la política en general, las instituciones y sus funciones, etc.

En este esquema de pensamiento, cada vez cobra más importancia la relación entre el individuo y la sociedad. Esto conduce a dos tipos de planteamientos: de un lado aquellos que pretenden entender el sistema social sin entrar demasiado en temas vinculados a relaciones de inequidad, como si hace el marxismo. Los primeros, conocidos como funcionalistas, resaltan el rol del individuo y su estatus en la sociedad, de la misma manera que tratan de analizar cómo actúa el individuo en el sistema y todo esto cómo se articula con la colectividad.

Al mismo tiempo, para la línea de orientación marxista, lo relevante será el peso relativo de las estructuras sobre el individuo y la tensión entre la clase dominante y las condiciones reales que se dan en la estructura de cada sociedad concreta. Estamos ante dos puntos de vista complementarios, pero en realidad se enfrentan como opuestos. De ahí, que los estudios sobre el conflicto social avanzan muy poco. No debemos olvidar que el siglo XX, entre otros importantes fenómenos sociales soportará dos guerras de orden mundial.

Finalmente, la ciencia se fija en la complementariedad de ambos puntos de vista para hacerlos coincidir en el paradigma del cambio social (Coller, 2007). Ahora la tensión entre la estructura y el individuo como una de las fuentes principales de conflicto, no estará reñida con el enorme potencial creativo que puede tener un conflicto en determinados momentos, al generar nuevas oportunidades de avance social.

No obstante, nuestro pensamiento va en la línea de que todo conflicto, al nivel que sea, posee una estructura también en el nivel de la relación microsociológica. Es decir, que existen importantes intuiciones con esta orientación de pensamiento que estamos examinando, de manera que creemos que estas ideas son también aplicables a nuestros conflictos diarios, salvando el nivel de la estructura social. Veremos más adelante esta cuestión.

\footnotetext{
${ }^{8}$ La obra de Bertalanffy (1976), "teoría General de los sistemas", va a abrir una nueva etapa en el pensamiento científico.

Estudios de la Paz y el Conflicto, Revista Latinoamericana, IUDPAS-UNAH, Volumen 1, Número 2, julio-diciembre 2020, pp. 92-110. DOI: 10.5377/rlpc.v1i2.9836
} 


\section{EL SISTEMA SOCIAL}

Un sistema de acción concreto, entendido como algo que se orienta hacia un fin social, es una estructura en la que hay elementos de motivación de las personas, culturales o simbólicos integrados en un orden dado. Esta idea procede del gran referente y estudioso de los sistemas sociales que fue Talcott Parsons (1902- 1979), profesor de sociología en la Universidad de Harvard. Su obra ilustra de manera aún no bien sobrepasada sobre los mecanismos insertados en los sistemas sociales.

Parsons (1999) plantea también el problema del orden social. Es decir, el problema del poder y como ejercerlo en un sistema social. Además de esto, el autor plantea diversos escenarios a partir de lo que denomina "la acción social". Entiende por acción social cualquier conducta, formula pues una teoría general muy amplia que abarca desde las relaciones matrimoniales al campo internacional.

Desde el punto de vista del autor que estamos comentando, toda acción social tiene que ser interpretada en un marco de referencia, lo que es coherente con los puntos de vista actuales sobre el significado de los actos. Se refiere al contexto biológico, que hoy diríamos genético con mayor precisión. $\mathrm{O}$ sea, los condicionantes personales centrados en la herencia. También al psiquismo, que sería el contexto en el que se mueve la personalidad de cada cual. También un contexto social, donde podemos incluir las interacciones con los demás, entre personas y grupos. Y finalmente, el contexto más amplio de una cultura determinada. En resumen, que el contexto da sentido a toda acción individual y por lo tanto su análisis es totalmente relevante.

Aunque el análisis parsoniano es muy detallado en muchos aspectos, a los efectos que nos interesan cabe destacar los cuatro elementos fundamentales que configuran la estructura del sistema social. Examinemos el siguiente cuadro (Tabla 1):

\section{Tabla 1. Componentes del Sistema Social en T. Parsons}

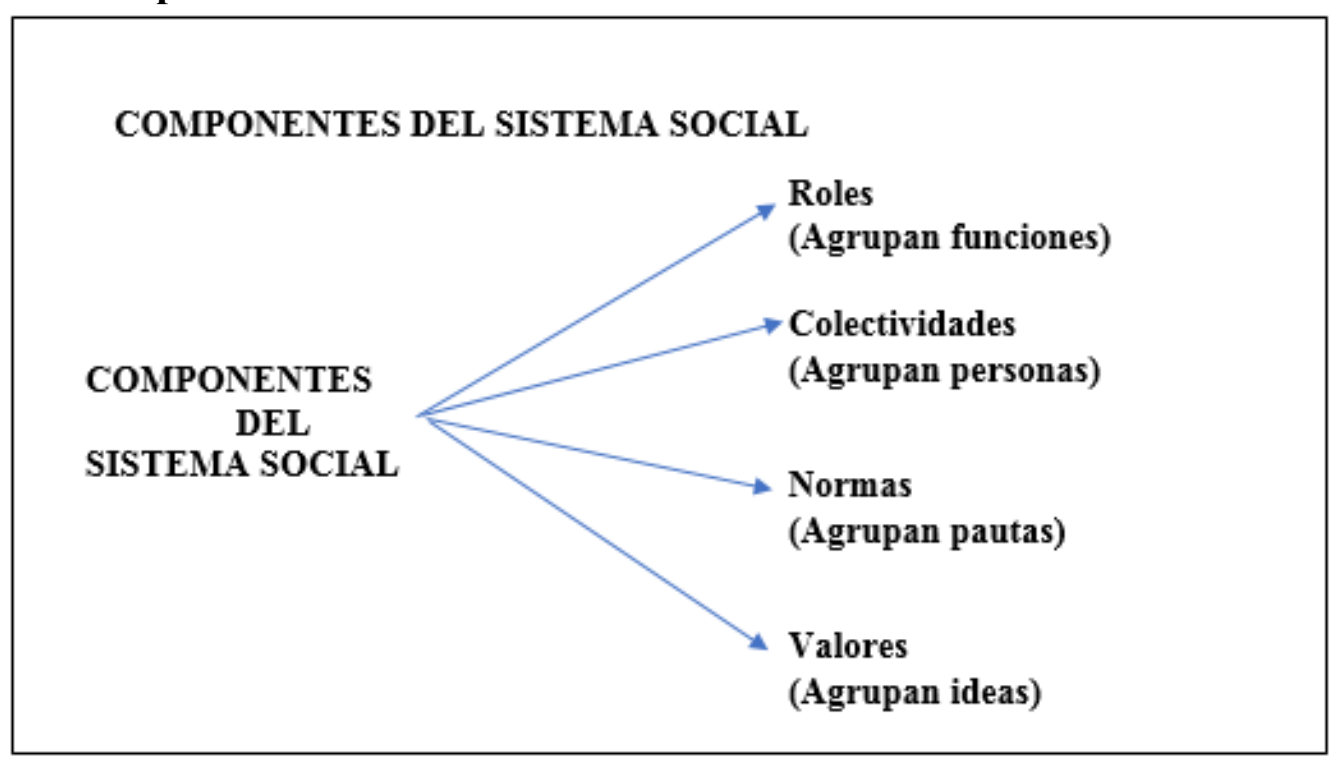

Fuente: Munné (1996), sobre ideas de Parsons (1999), en Entre el individuo y la sociedad. Adaptación de Redorta (2002). 
En los conflictos estructurales pensamos que es importante centrarse mucho en las relaciones de poder. Reducir la asimetría es un parámetro fundamental y sirve tanto para un conflicto con una multinacional, un gobierno, dos estados, una familia o cualquier organización.

Pensamos que algunos de los elementos que configuran cualquier conflicto estructural son los siguientes:

1) La existencia de CRONIFICACIÓN. Se trata de conflictos estancados y que se han incrustado en el sistema social.

2) La existencia de un alto componente IDEOLÓGICO muchas veces asentado en la búsqueda a toda costa del beneficio económico, el poder, la gloria, la vida futura, el racismo u otras creencias que se expresan en los relatos.

3) La CONCIENCIACIÓN de la situación conflictiva en sus diversos grados y capas sociales, particularmente en las partes cuya relación de poder es más débil.

4) La DISTRIBUCIÓN DEL PODER que tiende a ser muy asimétrica en todos los casos, comprendiendo la ausencia o el fracaso de los mecanismos de contrapeso o regulación.

5) El examen de la HISTORIA DEL CONFLICTO permite hallar un fuerte componente de esfuerzos anteriores fracasados.

6) La percepción de INSUFICIENCIA DE RECURSOS para hacer frente a la situación planteada.

Contrariamente a lo que acostumbra a creerse, sostenemos que los conflictos estructurales se dan igualmente en los órdenes micro sociales. Una familia tiene también su propia estructura y roles que pueden tener elementos de mucha estabilidad como padre, madre e hijos. Las pequeñas comunidades tienen también su propia estructura tal y como ha enseñado la dinámica de grupos.

\section{CÓMO SE CRONIFICAN LOS CONFLICTOS}

Todos conocemos conflictos que se alargan en el tiempo. El principal motivo acostumbra a ser la inhibición de aquellos que tendrían capacidad de intervenir para hallar soluciones, pero que, por un motivo u otro, casi siempre basado en un análisis coste versus beneficio, optan por dejar las cosas tal como estén. Imaginemos cualquier conflicto relacionado con la contaminación. Sea una empresa que en su día no adoptó medidas anticontaminación y que el coste de implantarlas supone el cierre del centro de trabajo único en una zona concreta. No hay una solución a corto plazo buena y a largo plazo las soluciones propuestas harán que el problema se agrave. En este caso, podremos ver muy posiblemente el traspaso de responsabilidad de unas personas a otras.

Los conflictos cronificados tienen fases de agudización y tienden a resolverse únicamente respecto de las consecuencias de lo que hoy sucede, pocas veces en las causas o en la raíz que resolvería la cuestión. Un conflicto relacionado con el reparto del agua cuando las necesidades han cambiado con el tiempo tiende a convertirse en un conflicto de recursos escasos hídricos. Si la lluvia es insuficiente, las infraestructuras a crear suponen una fuerte inversión financiera, tal vez no disponible. El régimen de lluvias, si se vuelve escaso, puede agudizar el conflicto de base. 
Las decisiones administrativas no adoptadas con anticipación o poco transparentes o directamente injustas, acostumbran a ser otra fuente de cronificación. Una cascada de recursos judiciales permite ver claro que se tardarán años en hallar una solución satisfactoria. $\mathrm{Y}$, si ésta lo es, la implementación de la misma puede resultar imposible de aplicar.

Las relaciones de poder ambiguas o muy equilibradas pueden impedir tomar decisiones operativas en el momento oportuno. Sea el caso de una organización empresarial cuyos propietarios son poseedores de acciones al 50\% cada parte. En un desacuerdo trascendente no habrá capacidad de adoptar, imponiendo, la decisión que pueda corresponder. O bien, sea el supuesto de una red cooperativa donde los socios cooperadores son a su vez trabajadores. El gerente puede tener dificultades para imponer a la plantilla una decisión que el adoptaría dado su mayor nivel de conocimiento. Actualmente, ya muchas cooperativas asumen protocolos para evitar este tipo de conflictos.

El supuesto inverso con una situación de relaciones de poder muy desequilibradas a favor de una parte también permite mantener un statu quo y perpetuar un conflicto. La esclavitud ha estado directamente vigente hasta el siglo XIX. Una plantación de café que depende de una única comercializadora y no puede acceder a los mercados, es probable que mantenga salarios de pura supervivencia.

Un régimen político de terror, como existe en Corea del Norte, por poner un ejemplo, permite reprimir duramente la disidencia y autosostenerse en el tiempo. No obstante, para que esto sea posible, además de una relación ciudadano-líder totalmente desequilibrada, conviene generar mensajes a la población capaces de generar un relato mínimamente asumible por el pueblo.

La falta de habilidades para resolver problemas ya sea por las instituciones, ya sea por las personas a cargo de la situación es otra fuente de cronificación. No hay creatividad y las soluciones de ayer no sirven ¿qué hacer? Las personas tienden a evadir su responsabilidad para evitar sentimientos de culpa.

Como hemos visto, la cronificación de un conflicto puede llegar por varias vías. Sin embargo, la más importante y que convendrá explorar siempre se halla de alguna manera, siempre vinculada a las relaciones de poder y a su equilibrio o desequilibrio.

\section{EL ROL DE LA IDEOLOGÍA}

La ideología se configura como todo un conjunto de creencias sobre la sociedad y el mundo del que disponemos para orientar nuestras decisiones. En los conflictos estructurales la ideología, vista como una forma de pensar más o menos colectiva sobre algo, puede abarcar millones de personas. Así el cristiano comparte ideas contenidas en el Evangelio. El musulmán vive las del Corán. El sistema capitalista se nutre de las ideas sobre el mercado y la riqueza, el comunismo cree en la lucha de clases, etc.

Lo relevante es que toda persona tiene un conjunto de valores en los que se ha socializado. La familia, la escuela, grupos de referencia y los medios de comunicación son los principales constructores de esos valores que adoptamos. Los valores están formados por creencias con orientación moral. Vivimos en un mar de creencias que van desde creer en la ley de la gravedad hasta creer en las cosas más esotéricas del mundo. Nuestras creencias nos hacen ver el mundo de una manera concreta. El religioso verá fe o no en una situación concreta, 
mientras que el financiero pensará en términos de dinero. Hay que tenerles mucho respeto a las creencias. Por las creencias se mata y se muere.

Un conflicto estructural tiene en el nivel que sea un componente ideológico, a veces muy marcado. Crear beneficio para el accionista puede estar muy bien. Pero, si únicamente se piensa en el beneficio del accionista y no en retribuir a los otros factores que inciden en la producción de ese beneficio, puede resultar insostenible. Creer que la violencia revolucionaria es el único camino para la emancipación de la sociedad, puede suponer muchas muertes y dolor. Pensar que un dios puede resolver todos los problemas de este mundo puede conducir a la inacción. En resumen, no hay conflicto estructural que no tenga que ver con las ideas que circulan entre las partes.

De ahí, la importancia de los discursos o relatos de cada una de las partes en el conflicto. Examinar los valores implícitos en las explicaciones de los actores se ha vuelto absolutamente imprescindible. En los supuestos más agudos, los discursos son típicamente excluyentes sobre todo en momentos de polarización de los grupos afectados. Los grupos, a su vez, tienden a ser excluyentes si están muy cohesionados y viven sus creencias de manera intensa.

El Klu Klux Klan tiene una historia nefasta de ataque a los negros. A los grandes grupos económicos colombianos no les importa organizar paramilitares y matar líderes sociales como está actualmente ocurriendo en pleno proceso de supuesta paz en Colombia. Todo ejército se sostiene sobre una ideología que es la que permite activar a los hombres y mujeres hacia el combate. Sin embargo, los movimientos de objetores de conciencia tienen también su propia ideología que se opone a la militar.

La persuasión a todos los niveles permite impregnarnos poco a poco de ideas de todo tipo que van desde comprar productos determinados hasta convencernos de a qué partido votar o no votar. Influir en las masas y desde luego en cada persona forma parte de estrategias de poder muy sofisticadas.

El control de la mente, la creación de discursos y su difusión y aceptación social forman parte de la frontera más avanzada de la psicología al servicio del sistema dominante sea el que sea. Siempre se ha afirmado que en una guerra lo primero que muere es la verdad. Un conflicto estructural puede ser o no violento, pero lo que es seguro es que los mensajes van a ser tergiversados hasta niveles insospechables como estamos viendo cada día en los medios incluyendo las redes sociales.

La ideología impregna también las culturas y sus prácticas sociales. Esto hace que ante un mismo hecho la reacción social pueda ser muy distinta. La cultura es la lupa con la miramos la realidad social. En una cultura muy violenta, un muerto puede no ser relevante. Mientras, un asesinato en un grupo pacifista puede resultar del todo inexplicable.

\section{LA CONCIENCIACIÓN}

La toma de conciencia respecto de algo supone la capacidad de evaluar las consecuencias de lo que está sucediendo. Poniendo un ejemplo, en tanto no se conocían los efectos perniciosos del amianto sobre la salud, pudieron venderse sin ningún límite productos basados en amianto, particularmente en la construcción. Actualmente ya no, al menos, en España.

Ser consciente de algo supone volver a Freud (1982) y sus puntos de vista sobre los actos no conscientes que todos ejecutamos y sobre los que construyó toda una teoría de psicoanálisis en el siglo pasado. No obstante, creemos que el hecho de no ser consciente de

Estudios de la Paz y el Conflicto, Revista Latinoamericana, IUDPAS-UNAH, Volumen 1, Número 2, julio-diciembre 2020, pp. 92-110. DOI: $10.5377 /$ rlpc.vli2.9836 
ciertos hechos o fenómenos no necesita mayor profundización porque actualmente ser "inconsciente" realmente es ya un adjetivo y el público general lo conoce.

Se produce una alienación de la consciencia cuando ésta, ya sea, individualmente o de forma colectiva, se transforma de manera que aparece contradictoriamente con lo que cabría esperar de la condición social del sujeto a grupo. Fue marxismo y los pensadores alemanes quienes usaron ampliamente el término para referirse a la expropiación del valor del trabajo por el capitalismo. Sin embargo, el concepto se ha usado en casi todas las ramas sociales como la psicología, la política, la economía, etc., hoy puede verse el fenómeno del consumismo como una alienación producida por el mercado.

En los conflictos de orden estructural, la ausencia de conciencia de las consecuencias de los actos y procesos sociales, muchas veces por falta de información, tiene efectos que caracterizan el conflicto. Así, podemos llamar alienación del consumidor respecto de los productos alimenticios procesados y sus efectos sobre la salud. Alienación respecto a muchos productos financieros que se compran por mera confianza en la entidad bancaria como puso de manifiesto la crisis de las hipotecas subprime. La concienciación tiene que ver básicamente con la información relevante. La falta de información mantiene el nivel de inconsciencia.

Una brusca toma de conciencia de una realidad concreta puede tomar forma de un agravamiento o el desencadenamiento de un conflicto estructural, en cuanto la concienciación depende del nivel de información y de su credibilidad. La crisis bancaria de 2008 puso de manifiesto la fragilidad del sistema bancario produciéndose enormes retiradas de capital. Tanto la crisis de Argentina de 2002 con el llamado "corralito", como la de Grecia en 2010 concienciaron que el gobierno y la banca podían bloquear las retiradas de dinero en un momento dado y respecto de recursos propios depositados en el sistema. En el mismo caso cabe decir la pandemia actual de COVID-19, que ha implantado la conciencia de "distancia social".

En psicología de masas, Le Bon (1986) se considera relevante el prestigio social sobre todo de los líderes. El prestigio está vinculado a atributos del poder. El prestigio es una cualidad que se tiene o no se tiene. Cuando la imagen social de prestigio se rompe, se produce una toma de conciencia brusca que acostumbra a tener consecuencias sociales. La información fiable que revela que un líder bien valorado, en realidad, es un corrupto tiende a desestabilizar un país en el nivel político si los mecanismos de represión no son eficaces. En cualquier caso, nunca las consecuencias son neutras.

En otros términos, cuando se tiene una idea clara del nivel de conciencia de un problema concreto, deberá plantearse que rol está jugando la información y los medios de difusión en los actores sociales.

\section{EL EQUILIBRIO DEL PODER}

El poder es un concepto tan central en ciencias sociales como pueda serlo la energía en física o la escasez en economía. En los conflictos estructurales conviene una reflexión distinta si estos se refieren a grandes grupos humanos o a pequeños grupos humanos.

El poder es un concepto no fácil de definir por sus múltiples caras, pero del que todos tenemos experiencia y una idea implícita. Tomamos partido por la definición de Blau (1982: 97) sociólogo norteamericano fallecido en 2002 y autor de toda una teoría sobre el 
intercambio social. Fue discípulo de los grandes autores de su época y especialidad. Afirma de modo literal: "el poder es la capacidad de las personas o grupos para imponer su voluntad sobre otros a pesar de la resistencia utilizando el recurso al miedo, bien en la forma de retirar las recompensas bien en la forma de castigo, en la medida en que tanto las primeras como las segundas constituyen realmente una sanción negativa". Afirma también a continuación que esa capacidad debe ser recurrente. Es decir, con cierto nivel de permanencia y por tanto estructural, punto de vista que Blau adoptó en general. La amenaza de castigo a la resistencia debe ser percibida como suficientemente severa por las otras partes. La relación de poder se percibe asimétrica siempre, ya que una situación de interdependencia con igual fuerza significa - en realidad- carencia de poder.

En el cuadro siguiente (Tabla 2) puede verse un resumen sistematizado respecto a la cuestión que estamos desarrollando:

Tabla 2.- Alternativas a la obediencia frente al poder en Blau

\begin{tabular}{llll}
$\begin{array}{l}\text { Alternativas } \\
\text { la obediencia }\end{array}$ & $\begin{array}{l}\text { Condiciones de } \\
\text { independencia }\end{array}$ & $\begin{array}{l}\text { Requisitos del } \\
\text { poder }\end{array}$ & $\begin{array}{l}\text { Implicaciones } \\
\text { estructurales }\end{array}$ \\
\hline $\begin{array}{l}\text { 1. Ofrecer } \\
\text { incentivos }\end{array}$ & $\begin{array}{l}\text { Recursos } \\
\text { estratégicos }\end{array}$ & $\begin{array}{l}\text { Indiferencia a } \\
\text { lo que ofrecen } \\
\text { los otros }\end{array}$ & $\begin{array}{l}\text { Intercambio y } \\
\text { distribución } \\
\text { de recursos }\end{array}$ \\
$\begin{array}{l}\text { 2. Obtener los } \\
\text { servicios de } \\
\text { otras fuentes }\end{array}$ & $\begin{array}{l}\text { Alterrativas } \\
\text { disponibles }\end{array}$ & $\begin{array}{l}\text { Monopolio de lo } \\
\text { que necesitan } \\
\text { los otros }\end{array}$ & $\begin{array}{l}\text { Tasas de } \\
\text { competición y } \\
\text { de intercambio }\end{array}$ \\
$\begin{array}{l}\text { 3. Tomar los ser- } \\
\text { vicios por la } \\
\text { fuerza }\end{array}$ & $\begin{array}{l}\text { Fuerza } \\
\text { coercitiva }\end{array}$ & Ley y orden & $\begin{array}{l}\text { Organización } \\
\text { diferenciación }\end{array}$ \\
$\begin{array}{l}\text { 4. Resistir pres- } \\
\text { cindiendo de } \\
\text { los servicios }\end{array}$ & $\begin{array}{l}\text { Ideales que } \\
\text { hacen dismi- } \\
\text { nuir las ne- } \\
\text { cesidades }\end{array}$ & $\begin{array}{l}\text { Materialismo y } \\
\text { otros valores } \\
\text { relevantes }\end{array}$ & $\begin{array}{l}\text { Formación de } \\
\text { ideologias }\end{array}$ \\
\hline
\end{tabular}

Fuente: Blau (1982: 104)

Es de particular interés el examen donde pueden verse cuales son las principales alternativas a la obediencia. No hay que perder de vista que la obediencia es uno de los principales efectos del poder. A partir de las cuatro alternativas que presenta, sistematiza las condiciones de independencia, los requisitos y las implicaciones.

El poder es una relación. No es que una persona pueda tener todo el poder como en las dictaduras y regímenes tiránicos. Se tata que en el poder siempre hay grados de libertad. Así en una clase de una escuela el profesor puede tener aparentemente todo el poder, pero si los alumnos se ponen todos de acuerdo para no ir a clase, el conflicto está servido. En el año 2010 un grupo muy cohesionado de controladores aéreos en España adoptaron posiciones de reivindicaciones laborales con gran incidencia social, parecía que no tenía ningún tipo de solución el conflicto ya que su labor es esencial. Sin embargo, y sin entrar en detalles de este conflicto el Estado declaró el estado de alarma y se militarizó la navegación aérea. Desde entonces cambió la relación de poder entre los controladores aéreos y el Estado. 
No hay que olvidar tampoco el rol de las normas. El Derecho es el mecanismo que impide el uso de la fuerza. Pero, para que cumpla su función tiene que estar legitimado por los actores sociales. Cuando falla esa legitimación, el Derecho es pura imposición y produce un fenómeno conocido como "reactancia psicológica"9 que tiende a reconducir las situaciones al uso de la fuerza.

En resumen, la capacidad de agrupar recursos y medios para enfrentarse a una situación de conflicto va a depender del poder de cada una de las partes. El problema consiste en que para que este análisis y la composición de lugar sea eficiente, normalmente hace falta mucha información y detalle. Sin embargo, el poder que cuenta es el poder que cada parte percibe en el otro. Si creemos que tiene muchos recursos, la situación es distinta de si pensamos que los está agotando.

\section{LOS EFECTOS DEL PODER}

El principal efecto del poder es la restricción de la libertad del otro. Y cuanto más se restringe la libertad del otro más se desequilibra la relación de poder. Una relación de poder equilibrada, de alguna manera, es un "no poder". Pero para entender mejor esta relación equilibrio- desequilibrio es conveniente fijarse en algunos efectos más detallados del poder. Esencialmente son cuatro:
a) Obediencia
b) Indefensión aprendida
c) Reactancia psicológica
d) Dependencia

Fijémonos en la obediencia. La obediencia implica sumisión con todas sus connotaciones y matizaciones. Implica cierto nivel de cooperación con la fuente de autoridad. Esta obediencia fue estudiada en profundidad por Stanley Milgram (1983), en 1963 con su famoso experimento sobre obediencia ante la petición de someter a personas a descargas eléctricas y generó una fuerte reflexión posterior sobre el tema. Kelman (1983) estableció tres niveles de influencia social en los individuos y grupos: sumisión, identificación e internalización. La sumisión se produce por efecto de la orden o norma cuya autoridad se reputa legítima. No obstante, un nivel más allá está colaboración necesaria con la fuente de poder al asociarse a la creencia propia produce una identificación con su finalidad y le confiere cierto valor moral. En un paso más allá, esta orden o norma puede interiorizarse de tal manera que ni se nos ocurre discutir sobre la legitimidad de ésta. En este último supuesto, un monje de clausura no saldrá del convento "porque ya sabe que no tiene que salir". Es la asunción completa de la situación de sumisión. Uno de los últimos trabajos relevantes en este sentido, los efectuó Zimbardo (2018), al plantearse el porqué de la maldad, para tratar de explicar como la obediencia puede conducir a situaciones aberrantes como los supuestos de maltratos y torturas de la prisión de Abu Ghraib (Irak).

\footnotetext{
9 Una ampliación en profundidad de los conceptos relativos al poder verla en Redorta (2005). en la obra "El poder y sus conflictos"

Estudios de la Paz y el Conflicto, Revista Latinoamericana, IUDPAS-UNAH, Volumen 1, Número 2, julio-diciembre 2020, pp. 92-110. DOI: 10.5377/rlpc.v1i2.9836
} 
Un fenómeno particularmente interesante es el de la "sumisión libremente consentida". Los trabajos más relevantes al efecto han sido los de Joule y Beauvois (1998). Véase el fenómeno del trabajador a sueldo donde se produce un intercambio de obediencia por salario. Se trata de un supuesto de obediencia pactada y limitada. Posteriormente, este tipo de relación puede conducir a lo que se ha estudiado como psicología del compromiso, de manera que la identificación y aún, internalización de la situación, conduce a que el "obediente" asuma su labor con entusiasmo. Esto no únicamente ocurre en este tipo de relaciones laborales, en la sociedad civil y en las relaciones políticas podemos también descubrir este fenómeno, incluso en situaciones de deslegitimación de la autoridad.

Aunque a nuestros efectos nos interesa especialmente los fenómenos vinculados a la obediencia, no podemos olvidar hacer referencia a los otros aspectos que son relevantes. Así la reactancia psicológica ya mencionada, es un concepto que de la física se pasó a la psicología para destacar la resistencia casi innata a la obediencia. El proceso de socialización nos educa en la obediencia social desde niños, pero la resistencia a la imposición la llevamos con nosotros y en determinadas situaciones puede ser la fuente que conduzca a la rebelión o la desobediencia. Es una fuerza que tiende al equilibrio de poder por la vía de la resistencia.

La dependencia como efecto del poder conlleva a situaciones que se prolongan en el tiempo. Así una comunidad que depende del trabajo en una mina tratará de mantener la continuidad de ésta incluso aceptando costes sociales a largo plazo.

Pero, desde el punto de vista de los conflictos estructurales un fenómeno muy relevante puede que sea la "indefensión aprendida". Este concepto introducido en el año 1967 por Seligman (1995), expresa la situación de la creencia en la inutilidad de enfrentar a la fuente de autoridad. Se demostró que sucesivos fracasos en los intentos de oponerse y ganar grados de libertad, conducen a una situación en la que se opta por el "ahorro de recursos" para evitar más situaciones de frustración. La indefensión aprendida se halla vinculada a la depresión individual y al clima de desánimo en las sociedades.

Nos conviene pues, un análisis más o menos preciso de las relaciones de poder y para eso es conveniente examinar sus fuentes. La psicología de las organizaciones es la que más ha avanzado en este tipo de análisis ${ }^{10}$.

\section{LA CONDUCTA DESVIADA}

La toma de conciencia como de inequidad o de injusticia de una situación dada, si se supera la situación de indefensión aprendida y se generan expectativas de cambio puede conducir a una situación inicialmente de descontento y posteriormente a la aparición de movimientos sociales de oposición al poder. Esto será particularmente cierto en aquellos supuestos en que la fuente de poder se considere con escasa legitimación. No debemos olvidar que la autoridad es poder legitimado por las personas a quienes se aplica ese poder. La falta de reconocimiento de la autoridad como legítima estimula siempre procesos de desobediencia en sus diversos niveles.

En los conflictos estructurales en los que aparecen situaciones violentas según Tilly (2007:19) la autoridad trata de discriminar las conductas de personas o grupos de acuerdo a

\footnotetext{
10 Para un examen muy exhaustivo de las fuentes de poder en la organización la obra de Morgan (1990) "Imágenes de la organización”, citada en la bibliografía.

Estudios de la Paz y el Conflicto, Revista Latinoamericana, IUDPAS-UNAH, Volumen 1, Número 2, julio-diciembre 2020, pp. 92-110. DOI: 10.5377/rlpc.v1i2.9836
} 
como siguen la norma: conductas prescritas (estos son los obedientes), conductas toleradas (desobediencia ligera) y conductas prohibidas (oposición frontal y violenta).

La motivación de la conducta desviada puede apoyarse en alguna o todas de estas fuentes: el temor, el interés propio o el honor, ello de acuerdo con Kaplan (2000) ${ }^{11}$ Esto afecta tanto a los individuos como a los grupos. Cualquiera de estas fuentes por sí misma, es un potente mecanismo individual y social para promover situaciones de rebeldía que pueden ser con violencia o sin violencia. La desviación respecto a lo establecido produce incertidumbre y dudas. En otros términos, produce un conflicto pues cuestiona tanto la fuente de poder como la propia capacidad de enfrentamiento al mismo. A partir de ahí el resultado puede ser una situación negociada que sería un fenómeno de adaptación. O también, un fenómeno de rechazo que conlleva represión. La aceptación de la reivindicación tiene fuertes efectos sobre la estructura de poder si se refiere a cuestiones consideradas fundamentales por las partes en conflicto (Munné, 1986).

\section{ALGUNAS BASES PARA LA INTERVENCIÓN EN CONFLICTOS ESTRUCTURALES}

La acción de desbloqueo de conflictos cronificados acostumbra a poder hacerse a partir de agudizaciones o reagudizaciones de un conflicto. Aunque suele verse la pacificación como una solución del problema, la realidad es que si no se va a las raíces de éste siempre estamos resolviendo sobre las consecuencias. Naturalmente depende del tipo de problema. Un conflicto como se da actualmente en Chile que pretende un cambio de constitución y una mayor amplitud de derechos, no es lo mismo que un conflicto donde lo que se pretende es de un nivel claramente inferior; por ejemplo, cambiar el alcalde de una población, si estamos hablando de gobernanza. De la misma manera, conflictos estructurales en otras áreas pueden tener que afrontarse con recursos distintos, así en una empresa u organización cualesquiera.

El primer problema que aparece acostumbra a ser la desconfianza. El tiempo transcurrido acostumbra a dejar un poso evidente de desconfianza entre las partes que dificulta mucho cualquier solución. No en vano, la confianza es el cemento de la sociedad, en feliz expresión de Elster (1997). Vencer la desconfianza supone establecer reglas para liberar emociones negativas acumuladas durante mucho tiempo de tal manera que esto facilite el diálogo, si se dan condiciones para el mismo. Las técnicas de reconstrucción de confianza debieran ser dominadas por cualquier profesional ${ }^{12}$ de cierto nivel que desea afrontar un conflicto cronificado. La confianza está muy relacionada con las expectativas y la historia del conflicto en el pasado. Remover el pasado puede ser muy eficaz o no, depende de cómo se haga. La primera regla es crear las condiciones para que las cosas puedan ser dichas, lo que supone crear un entorno libre de amenazas y encontrar la manera de que la expresión comunicativa no afecte a la autoestima de nadie. En pequeños grupos hay técnicas concretas como la riña leal ${ }^{13}$ u otras, como la técnica de "silla vacía" que proviene de la psicología gestáltica. Y unas cuantas más. Sin embargo, cuando se trata de grandes grupos sociales deben aplicarse otro tipo de recursos como pueden ser la negociación por intermediarios (shuttle diplomacy), la

\footnotetext{
${ }^{11}$ La cita es de Ortega (2007), en su obra "la fuerza de los pocos".

${ }^{12}$ Para una ampliación del tema de la confianza y sus implicaciones ver el trabajo de Lewicki (2000) y Wiethoff (2000), citados en la biografía en el que hay una muy exhaustiva relación de fuentes

${ }^{13}$ Véase en la bibliográfica un artículo con la técnica específica en un caso práctico en organizaciones. Estudios de la Paz y el Conflicto, Revista Latinoamericana, IUDPAS-UNAH, Volumen 1, Número 2, julio-diciembre 2020, pp. 92-110. DOI: $10.5377 /$ rlpc.v1i2.9836
} 
formación de comisiones de la verdad, la apelación a instancias superiores, etc. Fue (Smelser 1995: 36) quien propuso que la acción social debe comprender:

a) La definición de los objetivos generalizados o lo que es lo mismo la intención que se tiene, lo que se pretende conseguir.

b) La concreción de las reglas que gobiernan la búsqueda de estos fines. O, en otras palabras, que está permitido y que no, al elegir los instrumentos de acción.

c) La movilización de energía. Se tata de activar los mecanismos motivadores del grupo social de que se trate.

d) Los instrumentos de la acción. El conjunto de recursos a utilizar con el dominio de expertise adecuado.

Este planteamiento que es válido para cualquier acción social tiene perfecta aplicación en el diseño de estrategias para hacer frente a conflictos estructurales que se han cronificado. La experiencia práctica nos ha demostrado que hay algunos aspectos que siendo muy obvios tienden a no tenerse en cuenta. Esta actitud conduce a errores importantes de diseño en las intervenciones profesionales que entendemos que deben ser muy pensadas.

Entendemos que desde el punto de vista del tercero interviniente es preciso plantearse lo siguiente:

1) Explorar que ha fallado para que las partes no hayan podido resolver sus divergencias por sí mismas.

2) Examinar que recursos tiene cada una de las partes: la personalidad de los contendientes y sus habilidades, los recursos económicos que están dispuestas a implicar en el proceso, también los recursos sociales de que disponen.

3) Considerar el sistema legal como recurso puntual con sus ventajas e inconvenientes y ponderar su posible utilidad en el proceso.

4) Evaluar las posibles transacciones en un esquema coste/beneficio, considerando no únicamente los beneficios económicos, sino todo tipo de intercambios posibles.

5) Imaginar el resultado final deseable para el conflicto a partir de las expectativas de las partes y su racionalización.

6) Ponderar el rol de posibles objetivos que puedan tener en común las partes en discordia como intereses comunes, hijos en común, intereses electorales, etc.

Acostumbra a suceder que la intervención de terceros se produce en un entorno donde la situación emocional es muy tensa y a veces puede resultar difícil mantener líneas de trabajo con ciertos niveles de racionalidad. Los acontecimientos se suceden deprisa y es fácil cometer errores dada la incertidumbre, producto del mismo proceso del conflicto y de la concreta intervención propuesta. Sin embargo, no deberíamos olvidar que al tratar de afrontar un conflicto crónico aparecen sorpresas que han estado como "congeladas en el tiempo" y que pueden alcanzar altos niveles de agresividad o de tensión. Manejar la tensión emocional con control requiere alta formación por el riesgo de agravar la situación. No obstante, se demuestra que inmediatamente ocurre una mayor fluidez de la comunicación y que el desahogo que se ha producido permite poner las bases de soluciones que antes parecían inaceptables. 


\section{LA DINÁMICA DE GRUPOS AMPLIOS}

Los conflictos estructurales tienden a generar grupos amplios de acción para obtener sus reivindicaciones. Los movimientos sociales responden a parámetros que es conveniente examinar desde el punto de vista del comportamiento colectivo. En 1921, Freud (2003:17) en su "Psicología de las masas y análisis de yo", razona así: "Las multitudes no han conocido jamás la sed de verdad. Piden ilusiones a las cuales no pueden renunciar. Dan siempre preferencia a lo irreal sobre lo real, y lo irreal actúa sobre ellas con la misma fuerza que lo real. Tienen una visible tendencia a no hacer distinción entre ambos". Con esta primera composición de lugar, cabe recordar que el comportamiento colectivo forma parte de la psicología social y también se ha estudiado en política y ciencias de la comunicación. Actualmente podemos hablar de masas virtuales a partir de los procesos de interacción las redes sociales.

A grandes rasgos, podemos verlo todo como un enfrentamiento entre fuerzas de control social y fuerzas de cambio que tratan de producir innovación. Las personas agrupadas masivamente reúnen características muy típicas. Así: son impulsivas, mantienen una fuerte inestabilidad emocional, su deseo más ferviente es crecer para ser más miembros, la densidad es también otra característica ya que las emociones se viven muy intensamente; en estas condiciones las masas humanas son muy sugestionables, crédulas y direccionables desde un liderato aceptado (Redorta, 2011).

Aunque la psicología de la protesta merece un amplio tratamiento, desde el punto de vista que aquí nos interesa es preciso mencionar el punto de vista de Canneti (2005: 147) que se refiere a "cristales de masa" como pequeños grupos que se organizan dentro de la colectividad con gran estabilidad e impulsan su desarrollo. Esta evolución tiende a convertirse en movimientos sociales amplios, como pueda ser el movimiento ecologista o feminista. Es preciso destacar que para entender un movimiento social debería examinar tres parámetros: su identidad (su propia singularidad), frente a quien se posiciona (quien es el adversario) y cuál es la causa u origen (el conflicto estructural subyacente y cronificado) ${ }^{14}$.

En definitiva, estamos sosteniendo que cuando nos hemos de confrontar a una situación de agitación masiva normalmente provocada por conflictos estructurales con violencia o sin ella, el nivel de calidad de la intervención debe ser muy alto, dado que estos procesos normalmente requieren tiempo y equipos bien formados para entender unos procesos sociales que siguen sus reglas propias y de las que se conoce más de lo que se piensa, aunque menos de lo que precisa.

Desde la biología, un francés (Berthoz, 2009), ha estudiado los procesos de decisión de las personas llegando a conclusiones que resultan útiles precisamente ante situaciones que parece que pueden desbordarnos. Frente a complejidad ha opuesto el concepto de "simplexité" de mala traducción al español ya que no es simplicidad, sino la idea de que nuestro cerebro acostumbra a disponer de varias soluciones para un mismo problema y que elige de manera rápida la solución más adecuada por vía de heurismos ${ }^{15}$. Aquello de que “a grandes problemas, grandes soluciones" parece pues que va teniendo sentido a medida que

\footnotetext{
${ }^{14} \mathrm{Al}$ menos es el punto de vista de Touraine, en cita de Javaloy, Rodriguez y Espelt (2004: 75).

${ }^{15}$ Un heurismo es un atajo mental, dicho brevemente. El concepto es usado, entre otros campos en psicología cognitiva. Para una ampliación véase Redorta (2007) “Entender el conflicto”, citado en la bibliografía. Estudios de la Paz y el Conflicto, Revista Latinoamericana, IUDPAS-UNAH, Volumen 1, Número 2, julio-diciembre 2020, pp. 92-110. DOI: 10.5377/rlpc.v1i2.9836
} 
la vida social nos enfrenta a situaciones cada vez más enrevesadas y la ciencia avanza al propio tiempo.

En última instancia, debemos señalar que determinados conflictos cronificados actualmente tienden a afrontarse desde la no-violencia activa ${ }^{16}$. La metodología implica el rechazo y vacío a las diferentes formas de discriminación y violencia; la desobediencia civil frente a la violencia institucionalizada; la organización y movilización social solidaria. Ejemplos los hemos tenido como la objeción al servicio militar, boicot a empresas o productos, manifestaciones pacíficas, bloqueos y no colaboración con fuerzas que se apoyen en la violencia estructural.

\section{CONCLUSIONES}

Creemos que la conflictología centrada en el estudio del conflicto de cualquier clase, deberá abarcar cada vez más campo para asumir la línea de trabajo de paz muy vinculada a conflictos de orden estructural. El campo profesional de la gestión de conflictos y mediación debe efectuar un importante giro para poder abarcar conflictos considerados intratables, ya que estos en realidad pertenecen al ámbito de los conflictos estructurales.

La naturaleza de los conflictos estructurales no ha sido bien estudiada y afecta tanto al nivel micro como al nivel macro sociológico. Hemos perfilado los elementos básicos de este tipo de conflictos para centrarnos en profundizar en cuatro de ellos: la cronificación, la ideología, la concienciación y la distribución del poder. Estos cuatro aspectos son aspectos que tienen una relevancia fundamental en orden a una intervención.

Tanto la historia de este tipo de conflictos que acostumbra a ser larga, como el análisis de los recursos de intervención en general no se han valorado a pesar de su trascendencia. Estimamos que ello requiere el estudio de un caso concreto para ilustrar en detalle las dificultades de esta tarea. No obstante, se apuntan algunas técnicas que se han demostrado útiles en el nivel micro y se destaca la necesidad de un conocimiento más profundo de los mecanismos que regulan el comportamiento colectivo y de los movimientos sociales.

Estas conductas sociales de grandes grupos o de orden violento deben ser tratadas por equipos especializados y no deberían evitarse las intervenciones profesionales. Antes bien, sostenemos que la gestión de conflictos de raíces profundas nos exige mejorar intensamente las habilidades del área profesional en la que trabajamos.

\section{REFERENCIAS}

Alos, D. (2017). "La técnica de la silla vacía" (última consulta: 27 de abril de 2020. Disponible en: https://lamenteesmaravillosa.com/la-tecnica-de-la-silla-vacia/.

Bertalanffy, L. (1976). Teoría General de los sistemas. México: Fondo de Cultura Económica.

Berthoz, A. (2009). La simplexité. Paris: Odile Jacob.

Blau, P. (1982). Intercambio y poder en la vida social. Barcelona: Hora.

\footnotetext{
${ }^{16}$ Hay una importante línea de teorización sobre este concepto también denominado "resistencia no-violenta" que entronca desde las clásicas ideas de Thoreau y Ghandi, hasta muy modernos autores como Gene Sharp y otros.

Estudios de la Paz y el Conflicto, Revista Latinoamericana, IUDPAS-UNAH, Volumen 1, Número 2, julio-diciembre 2020, pp. 92-110. DOI: 10.5377/rlpc.v1i2.9836
} 
Bohm, D. (2002). La totalidad y el orden implicado. Barcelona: Kairós.

Burton, J. (1990). Conflict Resolution and Provention. London: Palgrave Macmillan.

Canetti, E. (2005). Masa y poder. Barcelona: Random House Mondadori.

Coleman, PT. (2000). “Trust, Trust Development, and Trust Repair". En Morton Deutsch y Coleman, P., (Eds.) The Handbook of Conflict Resolution. San Francisco: Jossey Bass.

Coller, X. (2007). Canon sociológico. Madrid: Tecnos.

Elster, J. (1997). El cemento de la sociedad: las paradojas del orden social. Barcelona: Gedisa.

Freud, S. (1982). Psicopatología de la vida cotidiana. Madrid: Alianza.

Freud, S. (2003). Psicología de las masas. Madrid: Alianza.

Galtung, J. (2009). "Towards a Conflictology: A Quest for Trans-Disciplinarity". En Sandole, D., Byrne, S., Sandole-Staroste, I., y Senehi, J., (Eds.) Handbook of Conflict Analysis and Resolution. London: Routledge.

Giddens, A. (1984). La constitución de la sociedad. Buenos Aires: Amorrortu.

GOOGLE SCHOLAR.

https://scholar.google.com/scholar?hl=ca\&as sdt=0\%2C5\&q=\%22conflict + analysis $\% 22+\mathrm{adr}+\& \mathrm{btnG}=$ Consulta efectuada el 27.4.20

Javaloy, F.; Rodriguez, A. y Espelt, E. (2004). Comportamiento colectivo y movimientos sociales. Madrid: Pearson Prentice Hall.

Joule, R., Beauvois, J. (1998). La soumission libremente consentie. Paris: Presses Universitaires de France.

Kelman, H. (1983). "La influencia social y los nexos entre el individuo y el sistema social; más sobre los procesos de sumisión, identificación e internalización”. En Torregrosa, J., y Crespo, E., (Comps.) Estudios básicos de psicología Social. Barcelona: Centro de Investigaciones Sociológicas.

Kosko, B. (1995). El pensamiento borroso. Barcelona: Grijalbo-Mandadori.

Le Bon, G. (1986). Psicología de masas. Madrid: Morata.

Lévi-Strauss, C. (1987). Antropología estructural. Barcelona: Paidós.

Lewicki, R. y Wiethoff, C. (2000). "Trust, Trust Development, and Trust Repair". En Morton Deutsch y Peter Coleman (Eds.), The Handbook of Conflict Resolution. San Francisco: Jossey Bass.

López de Mántaras, R. (2018). "Prologo", La estructura del Conflicto. Córdoba: Almuzara. Mayer, BS. (2004). Beyond neutrality. San Francisco: Jossey-Bass.

Milgram, S. (1983). "Obediencia a la autoridad". En Ramón Torregrosa, J., y Crespo, E., (Comps.) Estudios básicos de psicología Social. Barcelona: Centro de Investigaciones Sociológicas.

Mitchel, C. (2014). La naturaleza de los conflictos intratables. Barcelona: ICIP.

Morgan, G. (1990). Imágenes de la organización. Madrid: Ra-ma.

Morin, E. (2001). Los siete saberes necesarios para la educación del futuro. Barcelona: Paidós.

Munné, F. (1986). Psicología social. Barcelona: CEAC.

Ortega, A. (2007). La fuerza de los pocos. Barcelona: Círculo de Lectores.

Parsons, T. (1999). El sistema social. Madrid: Alianza.

Redorta, J. (2005). El poder y sus conflictos. Barcelona: Paidós.

Redorta, J. (2007). Entender el conflicto. Barcelona: Paidós.

Estudios de la Paz y el Conflicto, Revista Latinoamericana, IUDPAS-UNAH, Volumen 1, Número 2, julio-diciembre 2020, pp. 92-110. DOI: 10.5377/rlpc.v1i2.9836 
Redorta, J. (2010). "Techniques for Resolution of Work Conflicts in Organisations: The Loyal Fight", Journal of Conflictology, 1(1), UOC.

Redorta, J. (2011). Hacia un mundo deseado. Lleida: Milenio.

Redorta, J. (2011). “Apropant-nos al conflicto estructural”. En Eduard Vinyamata (Comps.), Conflictes i conflictología. Barcelona: UOC.

Redorta, J. (2011). Gestión de conflictos: lo que necesita saber. Barcelona: UOC.

Seligman, M.E., (1995). Indefensión en la depresión, el desarrollo y la muerte. Madrid: Debate.

Smelser, N. (1995). Teoría del comportamiento colectivo. México: Fondo de Cultura Económica.

Tilly, C. (2007). Violencia colectiva. Barcelona: Hacer.

Ury, W., y Piatigorsky, J. (2000). Alcanzar la paz: diez caminos para resolver conflictos en la casa, el trabajo y el mundo. Barcelona: Paidós.

Vinyamata, E. (2014). Conflictología. Barcelona: Ariel.

Wagensberg, J. (2012). Más árboles que ramas. Barcelona: Tusquets.

Wallacher, R.R.; Coleman, P.T.; Nowak, A. et al. (2013). Attracted to conflict: Dynamic Foundations of Destructive Social Relations. Heidelberg: Springer.

Yarn, D. (1999). Dictionary of Conflict Resolution. San Francisco: Jossey Bass.

Zimbardo, P. (2018). El efecto Lucifer: el porqué de la maldad. Barcelona: Paidós.

\section{REFERENCIA DEL AUTOR}

Josep Redorta es abogado con larga trayectoria profesional. Doctor en Psicología Social por la Universidad de Barcelona. Graduado Social en la Escuela Social de Barcelona. Diploma en la Escuela de Administración de Empresas de Barcelona. Máster en Análisis y Conducción de Grupos. Cursó estudios de Psicología social en la Open University de Londres. Postgraduado en Análisis y Conducción de Grupos en las Organizaciones por la Universidad de Barcelona. Postgraduado en Análisis y Conducción de Grupos en Educación también en la Universidad de Barcelona. Experto Internacional en Gestión de Conflictos. Su especialidad es el análisis de conflictos donde ha generado metodología propia. Ha trabajado la negociación y la mediación en distintos contextos. Conferenciante y consultor, tiene publicados numerosos libros.

Es miembro de varias organizaciones profesionales del sector, entre ellas The International Association of Conflict Management. Obtuvo el Premio AMMI 2012 por el conjunto de la obra publicada. La Universitat JAUME I y el Ayuntamiento de Vila-real (Castellón, España) instituyeron en 2014 el premio "JOSEP REDORTA" para trabajos de mediación policial; es miembro de honor en dos organizaciones profesionales dedicadas a la mediación. En septiembre de 2019 recibió el Premio ADR instituido por el Iltre. Colegio de Abogados de Barcelona en reconocimiento a la extensa y acreditada trayectoria de mediador de reconocido prestigio y su tarea pionera en favor de la promoción y consolidación de la mediación en la sociedad. Más información en: WWW.JOSEPREDORTA.CAT, josepredorta@icab.cat ORCID: 0000-0003-1144-0805

Estudios de la Paz y el Conflicto, Revista Latinoamericana, IUDPAS-UNAH, Volumen 1, Número 2, julio-diciembre 2020, pp. 92-110. DOI: 10.5377/rlpc.v1i2.9836 